\title{
Ocorrência de Doenças em Plantas Ornamentais Tropicais no Estado de Pernambuco
}

\author{
Severina R. O. Lins* \& Rildo S. B. Coelho \\ Laboratório de Fitopatologia, Empresa Pernambucana de Pesquisa Agropecuária - IPA, CEP 50761-000, Recife, PE, \\ e-mail: ninalins@globo.com
}

(Aceito para publicação em 16/09/2003)

Autor para correspondência: Severina Rodrigues de Oliveira Lins

LINS, S.R.O. \& COELHO, R.S.B. Ocorrência de doenças em plantas ornamentais tropicais no Estado de Pernambuco. Fitopatologia Brasileira 29:332-335. 2004

\begin{abstract}
RESUMO
As condições de cultivo das plantas ornamentais tropicais, relacionadas aos fatores precipitação, umidade, temperatura e densidade de plantio, favorecem a ocorrência de doenças que limitam a produção e reduzem a qualidade das flores. Destacaramse as doenças causadas por fungos e nematóides, sendo assinaladas a antracnose (Colletotrichum gloeosporioides) em Heliconia spp., Etlingera elatior, Tapeinochilos ananassae, causando lesões em folhas e inflorescências; manchas foliares (Bipolaris spp., Cercospora sp., Curvularia lunata, Glomerella cingulata, Guignardia sp. e Deigthoniella torulosa) em Heliconia spp., Calathea burle marx e Musa coccinea; podridão de rizomas e raízes (Rhizoctonia solani e Fusarium oxysporum f. sp. cubense) em E.

elatior e Heliconia chartacea cv. Sex Pink. As fitonematoses, causadas por espécies dos gêneros Meloidogyne, Radopholus e Helicotylenchus, constituem um dos principais problemas sanitários em ornamentais tropicais em Pernambuco, ocorrendo comumente em Alpinia purpurata, E. elatior, Zingiber espectabiles, Heliconia spp. e Musa spp. A espécie A. purpurata foi a mais suscetível a $M$. incognita. Em função dos trabalhos de erradicação pelos produtores, a murcha bacteriana (Ralstonia solanacearum raça 2) foi assinalada com baixa incidência nas áreas de cultivo de flores tropicais.

Palavras-chave adicionais: flores tropicais, fungos, nematóides.

\section{ABSTRACT}

Occurrence of diseases in ornamental tropical flowers in the state of Pernambuco

The climatic conditions in which tropical flowers are grown in Northeast Brazil, related to rainfall, humidity, temperature and cropping density factors, favor disease occurrence that limit and reduce the quality and yield of flowers. In this survey several diseases caused by fungi and nematodes were observed. Among them were the anthracnose (Colletotrichum gloeosporioides) on Heliconia spp, Etlingera elatior, Tapeinochilos ananassae, causing leaf and inflorescence lesions; leaf spots (Bipolaris spp., Cercospora sp., Curvularia lunata, Glomerella cingulata, Guignardia sp and Deighthoniela torulosa) on Heliconia app,

Calathea burle - marx and Musa coccinea; roots and rhizomes rots (Rhizoctonia solani and Fusarium oxysporum f. sp. cubense) on E. elatior and Heliconia chartacea cv. Sex Pink. Phytonematoses, caused by Meloidogyne spp., Radopholus sp. and Helicotylenchus sp. make up one of the main disease problems found in ornamental plants in the State of Pernambuco, usually occurring on Alpinia purpurata, E. elatior, Zingiber spectabiles, Heliconia spp. and Musa spp. Alpinia purpurata was found to be the most susceptible to $M$. incognita. On the other hand, the low incidence of bacterial wilt (Ralstonia solanacearum race 2) in the flower crop areas was associated with eradication carried out by flower producers.
\end{abstract}

A floricultura tropical é uma atividade que está em ascensão no Brasil e no mundo por destacar-se como um agronegócio gerador de renda, fixador de mão-de-obra no campo e adequado como cultura alternativa para pequenos produtores.

As principais espécies de flores tropicais pertencem às famílias Araceae, Heliconiaceae, Musaceae e Zingiberaceae, que vegetam naturalmente ou são exploradas em plantios convencionais na faixa tropical da América, Ásia e Pacífico Oeste (Assis et al, 2002). São plantas herbáceas, rizomatosas, perenes de reduzido porte ou arborescentes, caracterizadas por suas brácteas de cores e formas variadas, maior

* Bolsista CNPq/FACEPE-PE durabilidade pós-colheita, de grande beleza, utilizadas para ornamentação de ambientes.

A temperatura ideal para o cultivo das tropicais é entre 22 a $25^{\circ} \mathrm{C}$. No Brasil existem grandes plantações de flores tropicais, especialmente na região da mata úmida do Nordeste, com destaque para os estados de Pernambuco e Alagoas que já exportam suas flores para outros estados brasileiros (Lamas, 2002).

Em Pernambuco, as espécies de flores tropicais cultivadas pertencem às famílias Musaceae, Heliconiaceae, Costaceae, Zingiberaceae e Maranthaceae. Dentre as musas, destacam-se Musa coccinea Ander, M. velutina Ander, M. ornata Ander, que apresentam inflorescências de cores vermelhas, roxa e rosa. As helicônias envolvem as espécies 
Ocorrência de doenças em plantas ornamentais tropicais no...

mais importantes da floricultura tropical, com destaque para Heliconia psittacorum L. F., H. rostrata Ruiz \& Pavón, $H$. bihai (L.) L., H.stricta Humber, H. angusta Velloso e $H$. chartacea Lame ex Barreiros. A família Costaceae é constituída por quatro gêneros e 150 espécies, sendo Costus spicatus Susseng e Tapeinochilos ananassae Hassk. as espécies mais cultivadas. Nas zingiberáceas, destacam-se as espécies Zingiber spectabiles Griff, conhecida como "sorvete", Alpinia purpurata (Vieill.) Schum., comumente designada "panamá" e Etlingera elatior (Jack) R. M. Smith, denominada "bastão do imperador", com os tipos vermelho, rosa e porcelana. Dentro da família Maranthaceae destaca-se o gênero Calathea com as espécies Calathea burle-max $\mathrm{H}$. Kennedy (cristal), C. crotalifera Watson (cascavel) e C. lutea Kenney, conhecida como "charuto"(Chagas, 2000; Castro, 1995).

Na zona da mata de Pernambuco, os municípios que cultivam flores tropicais são de clima quente e úmido com precipitação anual variando de 1.600 a 1.800 milímetros. A umidade relativa varia de 70 a $95 \%$ e a temperatura média anual é de $24,1^{\circ} \mathrm{C}$ (Lamas 2002). Este clima favorece a ocorrência de doenças, as quais não têm sido estudadas. Assim sendo, existem poucas informações que auxiliam os produtores a identificar e controlar as doenças no campo, o que acarreta danos significativos nas plantações. Deve-se ressaltar que a expansão do cultivo e a utilização de mudas não certificadas contribuem para o aumento da incidência e severidade dos problemas fitossanitários na região.

No Brasil a questão fitossanitária de plantas ornamentais tem sido objeto de alguns trabalhos (Pitta,1995; Almeida et al, 1997), no entanto, as flores tropicais até então não estavam incluídas neste contexto, exceto pelos trabalhos de Assis (2002), que relata doenças e pragas em helicônias e Coelho \& Warumby (2002) sobre doenças e pragas em flores ornamentais tropicais na zona da mata de Pernambuco.

Este trabalho teve como objetivo relatar a ocorrência de doenças em plantas ornamentais tropicais na zona da mata de Pernambuco.

O levantamento foi realizado nos anos de 2001 e 2002, para identificar as doenças que afetam o cultivo das principais flores tropicais em Pernambuco. Foram realizadas visitas técnicas a 15 propriedades nos municípios de Camaragibe, Jaboatão, Igarassú, Paulista, Ribeirão, Água Preta e Cabo de Santo Agostinho. Em cada propriedade foram coletadas amostras de plantas infectadas e, nos casos de sintomas do ataque de nematóides, solo da rizosfera. As amostras foram acondicionadas em sacos plásticos e levadas ao Laboratório de Fitopatologia da Empresa Pernambucana de Pesquisa Agropecuária - IPA. A diagnose das doenças já assinaladas (Gillings, 1992; Sewake \& Uchida, 1995; Assis et al, 2002) foi feita considerando-se os sintomas e sinais, com auxílio de microscópio estereoscópico e ótico. As fitonematoses foram identificadas pela sintomatologia, presença de nematóides no sistema radicular, para os endoparasitas, e população do solo detectada pela extração por meio do método de flutuação centrífuga (Jenkins, 1964). Plantas com sintomas de vírus foram encaminhadas ao NAP/MEPA ESALQ/USP para diagnose. Foram feitos testes de patogenicidade em relação à antracnose e podridão do rizoma, no bastão do imperador e antracnose no tapeinóchilos. Para as antracnoses os fungos foram cultivados em meio batata-dextrose-agar (BDA) e a inoculação procedida pela deposição de discos de micélio e meio de cultura na superfície das brácteas com ferimentos superficiais promovidos por estilete. As inflorescências inoculadas foram mantidas em câmara úmida por $48 \mathrm{~h}$. Na podridão do rizoma o fungo foi isolado em BDA e, após sete dias de cultivo, foram retirados discos de micélio e meio de cultura das margens da colônia e depositada sobre ferimentos longitudinais no colo das plantas, abaixo do solo, as quais foram mantidas em vasos em casa-de-vegetação (Walcon et $a l, 1999)$. A freqüência de doenças e fitopatógenos foi avaliada em função do número de assinalamentos nas 15 propriedades visitadas.

Os testes de patogenicidade confirmaram Colletotrichum gloeosporioides Penz. como agente das antracnoses no bastão do imperador e tapeinóchilos e Rhizoctonia solani Kuhn como causador da podridão do rizoma, no bastão do imperador. Apenas uma virose foi detectada em tapeinóchilos, exibindo sintoma de faixa clorótica nas folhas, necrose das extremidades de ramos, nanismo e variegação e redução do tamanho da inflorescência. Seções ultrafinas do tecido foliar infetado revelaram a presença de partículas baciliformes características de vírus do gênero Rhabdovirus. A murcha bacteriana, causada por Ralstonia solanacearum (Smith) Yabuuchi et al. raça 2, foi assinalada em helicônia com baixa freqüência

Foi registrada a ocorrência de diversas doenças (Tabela 1), principalmente causadas por fungos e nematóides, nos municípios estudados. Dentre as doenças fúngicas, as mais freqüentes foram a antracnose $(C$. gloeosporioides) em helicônias e bastão do imperador, mancha de Bipolaris incurvata (M. B. Ellis) e de Curvularia lunata (Walker) Boedijn em helicônias e podridão do rizoma em bastão do imperador, causada por $R$. solani. Os nematóides causadores de doenças foram Meloidogyne incognita (Kofoid \& White) Chitwood, Helicotylenchus sp, Xiphinema sp e Radopholus sp ocorrendo em helicônias, musas, bastão do imperador, sorvete, tapeinóchilos e, de forma bastante severa, em alpínias. Nas regiões produtoras da zona da mata de Pernambuco a freqüência de fitopatógenos foi maior em relação a $C$. gloeosporioides (86\%), B. incurvata (86\%), C.lunata (86\%) e M. incognita (70\%). As freqüências de patógenos por família de hospedeiros avaliados são apresentadas na Figura 1. Foi constatada, em plantios de flores tropicais, a presença de importantes patógenos, tais como Fusarium oxysporum f.sp. cubense (E.F.Smith) Sn. \& Hansen e R. solanacearum, que mesmo numa freqüência bastante baixa, exigem medidas de controle, tais como utilização de mudas sadias e rotação de cultura, visando evitar aumento do inóculo e comprometimento da produção. 
S.R.O. Lins \& R.S.B. Coelho

TABELA 1 - Doenças detectadas em plantas ornamentais tropicais no estado de Pernambuco

\begin{tabular}{|c|c|c|c|}
\hline \multicolumn{2}{|c|}{ Cultura } & \multirow[b]{2}{*}{ Doença } & \multirow[b]{2}{*}{ Patógeno } \\
\hline $\begin{array}{l}\text { Nome } \\
\text { vulgar }\end{array}$ & Nome científico & & \\
\hline \multirow[t]{3}{*}{$\begin{array}{l}\text { Bastão do } \\
\text { Imperador }\end{array}$} & Etlingera elatior & Antracnose & $\begin{array}{l}\text { Colletotrichum } \\
\text { gloeosporioides }\end{array}$ \\
\hline & & $\begin{array}{l}\text { Podridão do } \\
\text { rizoma }\end{array}$ & Rhizoctonia solani \\
\hline & & Fitonematose & Meloidogyne incognita \\
\hline
\end{tabular}

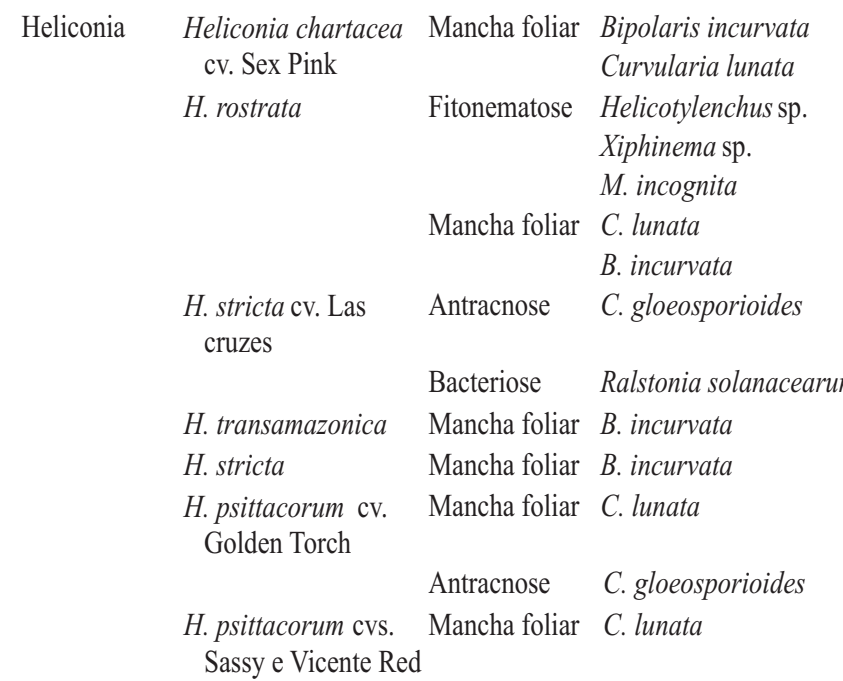

Sassy e Vicente Red

$\begin{array}{lll} & \text { Ferrugem } & \text { Puccinia heliconiae } \\ \text { H. psittacorum cv. } & \text { Podridão do } & \text { Fusarium oxysporum } \\ \text { Alan Carle } & \text { rizoma } & \text { f.sp. cubense } \\ \text { H. bihai } & \text { Mancha foliar } & \text { C. lunata } \\ & \text { Antracnose } & \text { C. gloeosporioides }\end{array}$

\begin{tabular}{|c|c|c|c|}
\hline \multirow[t]{4}{*}{ Musa } & Musa coccinea & Fitonematose & $\begin{array}{l}\text { M. incognita } \\
\text { Helicotylenchus sp. } \\
\text { Xiphinema sp. } \\
\text { Radopholus sp. }\end{array}$ \\
\hline & & Mancha foliar & $\begin{array}{l}\text { Deigthoniella torulosa } \\
\text { (Syd.) Ellis }\end{array}$ \\
\hline & M. velutina & Fitonematose & M. incognita \\
\hline & M. ornata & Fitonematose & $\begin{array}{l}\text { M. incognita } \\
\text { Xiphinema sp. } \\
\text { Helicotylenchus sp. }\end{array}$ \\
\hline Panamá & Alpinia purpurata & Fitonematose & $\begin{array}{l}\text { M. incognita } \\
\text { Xiphinema sp. } \\
\text { Dorylaimus sp. }\end{array}$ \\
\hline \multirow[t]{4}{*}{ Tapeinóquilos } & $\begin{array}{c}\text { Tapeinochilos } \\
\text { ananassae }\end{array}$ & Fitonematose & Helicotylenchus sp. \\
\hline & & Antracnose & C. gloeosporioides \\
\hline & & Mancha de alg & Cephaleuros virescens \\
\hline & & Faixa clorótica & Rhabdovirus \\
\hline
\end{tabular}
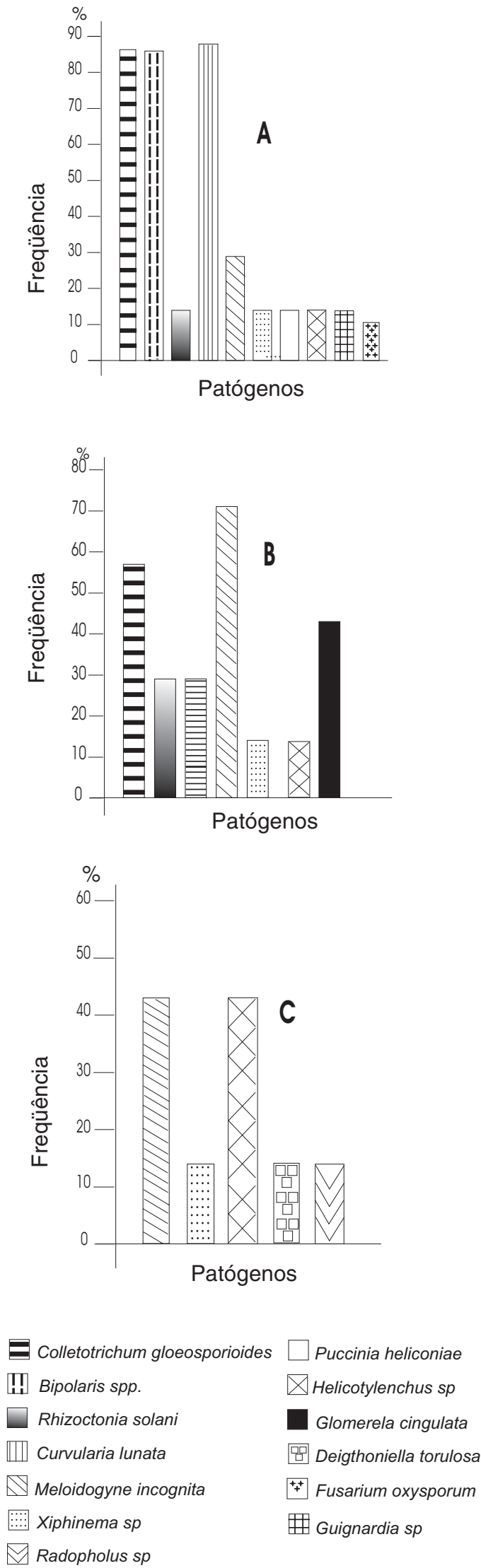

FIG. 1 - Frequiência de fitopatógenos nas famílias Heliconiaceae (A), Zingiberaceae (B) e Musaceae (C), no estado de Pernambuco. 
Ocorrência de doenças em plantas ornamentais tropicais no...

\section{REFERÊNCIAS BIBLIOGRÁFICAS}

ASSIS, S.M.P. Heliconia psittacorum L.f.- Doenças, pragas e utilização de rizobactérias na promoção de crescimento. (Tese de Doutorado). Recife. Universidade Federal Rural de Pernambuco. 2002.

ASSIS, S.M.P., MARINHO R.R.L., GONDIM Jr., M.G.C., MENEZES, M. \& ROSA, R.C. T. Doenças e pragas de helicônias. Diseases and pests of heliconias. Recife: UFRPE. 2002.

ALMEIDA, I.M.G., MALAVOLTA JUNIOR, V.A. \& IMEMES, S.L. Problemas Fitossanitários em Plantas Ornamentais. Instituto Biológico de Campinas, 1997.

CASTRO, C.E.F. Helicônia para exportação: aspectos técnicos da produção. Brasília, EMBRAPA-SPI, 1995. 44p (FRUPEX 16).

CHAGAS, A.J.C. Floricultura Tropical na Zona da Mata de Pernambuco. Recife: SEBRAE/PE, 2000.

COELHO, R.S.B. \& WARUMBY, J.F. Doenças e pragas de plantas ornamentais detectadas na Zona da Mata de Pernambuco.
Floricultura em Pernambuco. Série Agronegócio, SEBRAE-PE. 2002. pp.67-69.

GILLINGS, M. Bacterial wilt diseases in heliconia, ginger and banana:DNA based methods for detection and identification. Bulletin Heliconia Society International 6:13-16. 1992.

JENKINS, W.R. A rapid centrifugal flotation technique for extracting nematodes from soil. Plant disease reporter 48:692. 1964.

LAMAS, A.M. Floricultura Tropical: Técnicas de Cultivo. SEBRAE - PE. 2002.

PITTA, G.P.B. Aspectos fitossanitários de plantas ornamentais. In: Simpósio brasileiro de floricultura ornamental. 1995. Maringá. Simpósio... Maringá, 1999. pp.128-160.

SEWAKE, K.T. \& UCHIDA, J.Y. Diseases of heliconia in Hawaii. Research Extension series. Honololu: Institute of Tropical Agriculture and Human Resources. 1995.

WOLCAN, S.M.., LORI, G.A. RONCO, B.L. \& MONACO, C.I. Etiologia del marchitamiento y la podedumbre del talo del clavel en la Argentina. Fitopatologia Brasileira 24:564-566. 1999. 